\title{
Sexual Abuse Is Associated With an Abnormal Psychological Profile and Sleep Difficulty in Patients With Irritable Bowel Syndrome in Taiwan
}

\author{
Hsing-Feng Lee, ${ }^{1,2}$ Pei-Yi Liu, ${ }^{3}$ Yen-Po Wang, ${ }^{3,4,5}$ Chia-Fen Tsai, ${ }^{7}$ Full-Young Chang, ${ }^{5,6}$ and Ching-Liang Lu ${ }^{3,4,5,6 *}$ \\ ${ }^{I}$ Division of Gastroenterology, Department of Medicine, Dalin Tzu Chi Hospital, Buddhist Tzu Chi Foundation, Chia-Yi, Taiwan; ${ }^{2}$ School of \\ Medicine, Tzu Chi University, Hualien, Taiwan; ${ }^{3}$ Institute of Brain Science, ${ }^{4}$ Faculty of Medicine, National Yang-Ming University School of \\ Medicine, Taipei, Taiwan; and ${ }^{5}$ Endoscopic Center for Diagnosis and Treatment, ${ }^{6}$ Division of Gastroenterology, Departments of Medicine, \\ ${ }^{7}$ Psychiatry, Taipei Veterans General Hospital, Taipei, Taiwan
}

\section{Background/Aims}

Both sexual and physical abuse history have been reported to be associated with irritable bowel syndrome (IBS) in Western countries. The impact of abuse history in IBS patients in Asia remains unclear. We aim to determine the prevalence of abuse history, its associated psychological profiles, and sleep problems among IBS patients in Taiwan.

\section{Methods}

In total, 194 Rome III-defined IBS patients were invited to participate. Age- and sex- matched healthy carriers of chronic hepatitis B or hepatitis $C$ without chronic abdominal symptoms were identified as disease-controls. We administered a validated questionnaire to evaluate bowel symptoms, physical/sexual abuse history, anxiety/depression (Hospital Anxiety and Depression Scale [HADS]), and sleep quality.

\section{Results}

IBS patients had a significantly higher prevalence of sexual abuse history than the disease-control group both before (16.5\% vs $6.7 \%$, $P<0.05)$ and after $(16.0 \%$ vs $6.6 \%, P<0.05)$ adolescence. These significant differences were mainly observed in women $(13.4 \%$ vs $3.4 \%, P<0.05)$. No difference was noted in history of physical abuse between the 2 groups. IBS patients with a history of sexual abuse had significantly higher HADS scores and higher frequencies of sleep difficulty than those without.

\section{Conclusions}

In Taiwan, sexual abuse history was more prevalent in female IBS patients than controls. Sexual abuse history may contribute to higher anxiety/depression levels and sleep difficulties, which are commonly experienced in IBS patients. In Asia, abuse history should be obtained when approaching IBS patients to facilitate better management.

(J Neurogastroenterol Motil 2018;24:79-86)

Key Words

Depression; Irritable bowel syndrome; Physical abuse; Sexual abuse

Received: January 10, 2017 Revised: April 27, 2017 Accepted: July 12, 2017

(a) This is an Open Access article distributed under the terms of the Creative Commons Attribution Non-Commercial License (http://creativecommons. org/licenses/by-nc/4.0) which permits unrestricted non-commercial use, distribution, and reproduction in any medium, provided the original work is properly cited.

*Correspondence: Ching-Liang Lu, MD

Endoscopic Center for Diagnosis and Treatment, Taipei Veterans General Hospital, No. 201, Sec. 2, Shih-Pai Rd. Sec. 2, Taipei 112 , Taiwan

Tel: +886-2-2875-2111 (ext. 3385), Fax: +886-2-2873-9318, E-mail: cllu@ym.edu.tw; cllu@vghtpe.gov.tw 


\section{Introduction}

Irritable bowel syndrome (IBS) is characterized by chronic or recurrent abdominal pain/discomfort with altered bowel habits in the absence of structural or biochemical abnormalities. ${ }^{1}$ The actual pathophysiology of IBS remains unclear, although some studies have shown that it is associated with motility disorders, visceral hypersensitivity, previous gastrointestinal infection, psychological disorders, and gut dysbiosis, among others. ${ }^{2-5}$ The impact of IBS on society is very large in terms of the direct medical expenses and indirect social costs. ${ }^{6,7}$

In Western countries, childhood or adulthood abuse is associated with IBS and other functional gastrointestinal disorders (FGIDs). ${ }^{8}$ For example, Drossman et $\mathrm{al}^{9}$ found that FGID patients experienced more severe forms of abuse in childhood and/or adulthood, including rape. In a population-based study, Talley et $\mathrm{al}^{10}$ found that the rate of childhood abuse was significantly higher in IBS patients than in controls (15.4\% vs 9.5\%). Furthermore, experiences of abuse among IBS patients may lead to greater abdominal pain, poorer daily function, and more extra-intestinal symptoms. ${ }^{11,12}$ Despite the positive association between history of abuse and IBS, a study in Europe showed no significant differences between IBS patients and controls in terms of abuse history. ${ }^{13}$ Furthermore, IBS patients who reported previous abuse demonstrated significantly higher levels of current psychological distress. ${ }^{13}$

IBS has been reported to be associated with higher levels of anxiety and/or depression. ${ }^{14-16}$ Sleep difficulty is also common in IBS patients. ${ }^{17}$ Brain-gut dysfunction could be the underlying pathophysiology responsible for the extra-intestinal symptoms in IBS patients described above. ${ }^{18} \mathrm{~A}$ history of childhood sexual abuse is a well-known major risk factor for psychological problems in adulthood. ${ }^{19}$ Whether this abuse history contributes to anxiety, depression or even sleep difficulty among IBS patients remains unclear. Eastern and Western societies differ in many ways in terms of their cultures as well as the medical, social, economic, and political environments. To the best of our knowledge, the role of sexual and physical abuse in IBS patients has not been examined in Asia. Thus, we aim to determine whether a history of sexual and physical abuse was higher in IBS patients than in control patients in Taiwan. We also evaluated the associations between psychological profiles (anxiety and depression) and sleep difficulty and abuse history in IBS patients.

\section{Materials and Methods}

\section{Subjects}

Male and female IBS patients who were over 18 years of age were consecutively recruited from outpatient clinics in Taipei Veterans General Hospital, a tertiary medical center in Northern Taiwan from January 2011 to December 2011. The diagnosis of IBS was based on the Rome III criteria. After a detailed explanation about the way to fill the questionnaires (see below) from a research assistant, these patients were asked to complete the questionnaires at a quiet and private room beside the clinic. A separate age- and sexmatched diseased-control group was invited to participate in the study at the same clinic. The disease-controls consisted of healthy carriers of chronic hepatitis B or C without symptoms of FGIDs. The patients in the disease-control group were clinically asymptomatic and were enrolled during their regular surveillance visits for chronic hepatitis $\mathrm{B}$ or $\mathrm{C}$. The patients in both groups had not taken any anti-depressive or anxiolytic medications and had not visited the psychiatric clinics in the past 3 months prior to the enrollment. The study was approved by the Institutional Review Board of Taipei Veterans General Hospital (IRB No. 201012020IC), and all subjects signed a written informed consent form before the start of the study.

\section{Questionnaire}

All questionnaires were conducted in a comfortable and confidential place to ensure anonymity. The participants were asked to self-complete the questionnaire based on the explanations provided by research assistants.

\section{Bowel symptom questionnaire}

We used a standardized questionnaire modified from a previously validated one to assess the presence of IBS and other FGIDs based on Rome II questions. ${ }^{17}$ Briefly, the presence of a Rome III diagnosis of IBS was based on the presence of recurrent abdominal pain or discomfort for at least 3 days/month for the past 3 months that involved 2 of three features: improvement in symptoms with defecation and onset associated with a change in the frequency of stools or in the form (appearance) of stools.

\section{Sleep questionnaire}

Sleep quality was evaluated by a questionnaire that was validated in a prior study. ${ }^{17}$ Sleep difficulty was defined as abnormal 
sleep in the last 6 months with difficulty falling asleep, waking up repeatedly during the night, waking up in the morning yet feeling tired and not rested, or the inability to sleep without a sleeping pill or other sleeping aid. ${ }^{17}$

\section{Hospital Anxiety and Depression Scale}

We measured the degree of psychological distress in IBS patients using the Hospital Anxiety and Depression Scale (HADS). The individual subscales reflecting anxiety and depression comprise 7 questions rated on a score of $0-3$, for a total potential score of $0-21$. The 2 subscales can be summed to provide anxiety and depression scores (range: 0-42). High HADS scores indicate poor mental health. A score of 11 was chosen as the cut-off, which has previously been validated. ${ }^{20}$

\section{Sexual and physical abuse questionnaire}

The modified Chinese version of an abuse history questionnaire was translated from the English version; the Chinese version has been previously validated. ${ }^{21}$ This questionnaire has been extensively adopted to study history of abuse in FGIDs ${ }^{21}$ and has 2 major components: sexual and physical abuse. The sexual abuse component is divided into 2 age groups with a cut-off of 14 years to differentiate between before and after adolescence. Items include "Has anyone ever exposed the sex organs of their body to you when you did not want it? Has anyone ever threatened to have sex with you when you did not want to? Has anyone ever touched the sex organs of your body when you did not want this? Has anyone ever made you touch the sex organs of their body when you did not want this? Has any- one ever forced you to have sex when you did not want this?" The physical abuse component is also divided with the same age cut-off as sexual abuse. Items to evaluate physical abuse include "Has an older person ever done the following: hit, kick or beat you or seriously threaten your life?"

\section{Statistical Methods}

Student's $t$ test and chi-square test were used to evaluate history of abuse between the IBS patients and controls. The statistical

Table 1. Demographic Data of Irritable Bowel Syndrome Patients and Diseased-controls

\begin{tabular}{lcccc}
\hline \multicolumn{1}{c}{ Variables } & IBS patients & Controls & $t$ score & $\chi^{2}$ score \\
\hline Age (mean \pm SD, yr) & $46.3 \pm 13.1$ & $45.0 \pm 13.0$ & $0.95^{\mathrm{a}}$ & \\
Sex (\% female) & $104(53.6 \%)$ & $104(53.6 \%)$ & $0.0^{\mathrm{a}}$ \\
Bowel habit type (n) & & & \\
$\quad$ IBS-D & 91 & NA & \\
IBS-C & 60 & NA & \\
IBS-M & 37 & NA & \\
IBS-U & 6 & NA & \\
Education (n) & & & \\
Elementary school & 10 & 6 & \\
Junior high school & 14 & 13 & \\
Senior high school & 37 & 52 & \\
University or college & 109 & 96 & \\
Post-graduate & 24 & 27 & \\
\hline
\end{tabular}

${ }^{a}$ Not significant.

IBS, irritable bowel syndrome; $\chi^{2}$, Pearson's chi-square test; IBS-D, diarrheapredominant IBS; IBS-C, constipation-predominant IBS; IBS-M, mixed IBS; IBS-U, unsubtyped IBS; NA, not applicable.

Table 2. Sexual and Physical Abuse History in Irritable Bowel Syndrome Patients and Controls

\begin{tabular}{|c|c|c|c|c|c|c|}
\hline \multirow[b]{2}{*}{ Variables } & \multicolumn{3}{|c|}{ Before adolescence } & \multicolumn{3}{|c|}{ After adolescence } \\
\hline & $\begin{array}{c}\text { IBS patients } \\
(\mathrm{n}=194)\end{array}$ & $\begin{array}{l}\text { Controls } \\
(\mathrm{n}=194)\end{array}$ & $\chi^{2}$ score & $\begin{array}{l}\text { IBS patients } \\
(\mathrm{n}=194)\end{array}$ & $\begin{array}{l}\text { Controls } \\
(\mathrm{n}=194)\end{array}$ & $\chi^{2}$ score \\
\hline \multicolumn{7}{|l|}{ Sexual abuse (n [\%]) } \\
\hline Any sexual abuse & $32(16.5)$ & $13(6.7)$ & $9.1^{\mathrm{a}}$ & $31(16.0)$ & $15(7.7)$ & $6.3^{\mathrm{a}}$ \\
\hline Sexual exposure & $20(10.3)$ & $10(5.2)$ & & $17(8.8)$ & $12(6.2)$ & \\
\hline Threat of sex & $3(1.5)$ & $1(0.5)$ & & $6(3.1)$ & $1(0.5)$ & \\
\hline Touched patient & $8(4.1)$ & $1(0.5)$ & & $6(3.1)$ & $2(1.0)$ & \\
\hline Patient touched other & $14(7.2)$ & $1(0.5)$ & & $10(5.2)$ & $4(2.1)$ & \\
\hline Rape or incest & $9(4.6)$ & $5(2.6)$ & & $11(5.7)$ & $2(1)$ & \\
\hline Physical abuse (often) (n [\%]) & $43(22.2)$ & $36(18.6)$ & $0.8^{\mathrm{b}}$ & $21(10.8)$ & $13(6.7)$ & $2.1^{\mathrm{b}}$ \\
\hline Either sexual or physical abuse (n $[\%]$ ) & $53(27.3)$ & $39(20.1)$ & $2.8^{\mathrm{b}}$ & $38(19.6)$ & $26(13.7)$ & $3.1^{\mathrm{b}}$ \\
\hline Both sexual and physical abuse (n [\%]) & $11(5.7)$ & $5(2.6)$ & $3.0^{\mathrm{b}}$ & $7(3.6)$ & $1(0.5)$ & $3.6^{\mathrm{b}}$ \\
\hline
\end{tabular}

${ }^{\mathrm{a} P}<0.01$.

${ }^{\mathrm{b}} \mathrm{Not}$ significant.

$\chi^{2}$, Pearson's chi-square test; IBS, irritable bowel syndrome. 
analysis was performed using SPSS 17.0 software (IBM Corp, Armonk, NY, USA).

\section{Results}

\section{Sexual and Physical Abuse History}

In total, 194 Rome-III defined IBS patients (female, 104; mean age $46.3 \pm 13.1$ years) were invited to complete the questionnaires on FGID and abuse history. In the diseased-control group, the mean age was $45.0 \pm 13.0$ years, with a similar gender distribution as in the IBS group. The characteristics of both groups are provided in Table 1. Of the IBS patients, 91 (46.9\%) were classified as diarrhea-predominant, 60 (30.9\%) as constipation-predominant, 37 $(19.1 \%)$ as mixed, and $6(3.1 \%)$ as unclassified. IBS patients had a higher prevalence of sexual abuse history than the control group, both before ( $16.5 \%$ vs $6.7 \%, P<0.01)$ and after $(16.0 \%$ vs $7.7 \%$, $P<0.05$ ) adolescence (Table 2). On the other hand, no difference was noted in the history of physical abuse between IBS patients and controls, either before $(22.2 \%$ vs $18.6 \%, P=0.377)$ or after $(10.8 \%$ vs $6.7 \%, P=0.151$ ) adolescence.

\section{Gender Differences in Sexual and Physical Abuse}

A gender difference was noted in the prevalence of sexual and physical abuse in the IBS group. Female IBS patients had a significantly higher rate of sexual abuse history both before $(13.4 \%$ vs $4.1 \%, P=0.001)$ and after $(14.4 \%$ vs $7.2 \%, P=0.010)$ adolescence than controls (Table 3 ). Furthermore, female IBS patients also had a higher rate of physical abuse after adolescence than controls $(7.7 \%$ vs $3.1 \%, P=0.030)$. However, similar rates of sexual and physical abuse history between male IBS patients and controls were noted both before and after adolescence.

Table 3. Gender Difference in Sexual and Physical Abuse History in Irritable Bowel Syndrome Patients and Controls

\begin{tabular}{|c|c|c|c|c|c|c|c|}
\hline & \multirow[b]{2}{*}{ Gender } & \multicolumn{3}{|c|}{ Before adolescence } & \multicolumn{3}{|c|}{ After adolescence } \\
\hline & & $\begin{array}{l}\text { IBS patients } \\
(\mathrm{n}=194)\end{array}$ & $\begin{array}{l}\text { Controls } \\
(\mathrm{n}=194)\end{array}$ & $\chi^{2}$ score & $\begin{array}{l}\text { IBS patients } \\
(\mathrm{n}=194)\end{array}$ & $\begin{array}{l}\text { Controls } \\
(\mathrm{n}=194)\end{array}$ & $\chi^{2}$ score \\
\hline \multirow[t]{2}{*}{ Sexual abuse (n [\%]) } & $\mathrm{F}$ & $26(13.4)$ & $8(4.1)$ & $9.1^{\mathrm{a}}$ & $28(14.4)$ & $14(7.2)$ & $6.3^{\mathrm{a}}$ \\
\hline & M & $6(3.1)$ & $5(2.6)$ & & $3(1.5)$ & $1(0.5)$ & \\
\hline \multirow[t]{2}{*}{ Physical abuse (n [\%]) } & $\mathrm{F}$ & $27(13.9)$ & $19(9.8)$ & $0.8^{\mathrm{b}}$ & $15(7.7)$ & $6(3.1)$ & $2.1^{\mathrm{b}}$ \\
\hline & M & $16(8.2)$ & $17(8.8)$ & & $6(3.1)$ & $7(3.6)$ & \\
\hline
\end{tabular}

${ }^{\mathrm{a}} \mathrm{P}<0.01$.

${ }^{\mathrm{b}}$ Not significant.

$\chi^{2}$, Pearson's chi-square test; IBS, irritable bowel syndrome; F, female; M, male.

Table 4. Hospital Anxiety and Depression Scale and Sleep Disorders in Irritable Bowel Syndrome Patients With and Without a History of Abuse

\begin{tabular}{|c|c|c|c|c|c|c|c|c|}
\hline & \multicolumn{4}{|c|}{ Sexual abuse } & \multicolumn{4}{|c|}{ Physical abuse } \\
\hline & Abuse & Non-abuse & t score & $\chi^{2}$ score & Abuse & Non-abuse & t score & $\chi^{2}$ score \\
\hline \multicolumn{9}{|c|}{ Before adolescence (Mean $\pm \mathrm{SD})$} \\
\hline HADS & $22.0 \pm 6.2$ & $13.1 \pm 6.1$ & $-9.4^{a}$ & & $15.6 \pm 7.4$ & $14.4 \pm 6.9$ & $-0.9^{c}$ & \\
\hline HADS-A & $11.1 \pm 3.3$ & $6.8 \pm 3.3$ & $-7.5^{\mathrm{a}}$ & & $8.1 \pm 4.1$ & $7.4 \pm 3.6$ & $-0.3^{c}$ & \\
\hline HADS-D & $10.7 \pm 3.7$ & $6.6 \pm 3.9$ & $-8.4^{\mathrm{a}}$ & & $7.5 \pm 3.6$ & $7.2 \pm 4.2$ & $-0.9^{c}$ & \\
\hline Sleep disorders & $22 / 31(71.0 \%)$ & $65 / 163(39.9 \%)$ & & $6.7^{\mathrm{b}}$ & $11 / 21(52.4 \%)$ & $76 / 173(43.9 \%)$ & & $0.4^{\mathrm{c}}$ \\
\hline \multicolumn{9}{|c|}{ After adolescence $($ Mean $\pm \mathrm{SD})$} \\
\hline HADS & $22.0 \pm 6.2$ & $13.1 \pm 6.1$ & $-7.4^{\mathrm{a}}$ & & $15.6 \pm 7.4$ & $14.4 \pm 6.9$ & $-0.7^{\mathrm{c}}$ & \\
\hline HADS-A & $11.1 \pm 3.3$ & $6.8 \pm 3.3$ & $-6.8^{\mathrm{a}}$ & & $8.1 \pm 4.1$ & $7.4 \pm 3.6$ & $-0.8^{\mathrm{c}}$ & \\
\hline HADS-D & $10.7 \pm 3.7$ & $6.6 \pm 3.9$ & $-5.4^{\mathrm{a}}$ & & $7.5 \pm 3.6$ & $7.2 \pm 4.2$ & $-0.3^{\mathrm{c}}$ & \\
\hline Sleep disorders & $22 / 31(71.0 \%)$ & $65 / 163(39.9 \%)$ & & $10.1^{\mathrm{b}}$ & $11 / 21(52.4 \%)$ & $76 / 173(43.9 \%)$ & & $0.5^{c}$ \\
\hline
\end{tabular}

a $P<0.001$.

${ }^{\mathrm{b}} \mathrm{P}<0.01$.

${ }^{\mathrm{c}}$ Not significant.

$\chi^{2}$, Pearson's chi-square test; HADS, Hospital Anxiety and Depression Scale; HADS-A, HADS including anxiety subscale; HADS-D, HADS including depression subscale. 
Table 5. Relationship Between Subtype of Irritable Bowel Syndrome and Abuse History

\begin{tabular}{|c|c|c|c|c|c|}
\hline & IBS-D $(n=91)$ & IBS-C $(n=60)$ & IBS-M $(\mathrm{n}=37)$ & IBS-U $(n=6)$ & $\chi^{2}$ score \\
\hline \multicolumn{6}{|l|}{ Sexual abuse (n [\%]) } \\
\hline Before adolescence & & & & & $2.2^{\mathrm{a}}$ \\
\hline Abuse & $18(19.8)$ & $9(15.0)$ & $5(13.5)$ & $0(0.0)$ & \\
\hline No abuse & $73(80.2)$ & $51(85.0)$ & $32(86.5)$ & $6(100.0)$ & \\
\hline After adolescence & & & & & $2.0^{\mathrm{a}}$ \\
\hline Abuse & $18(19.8)$ & $7(11.7)$ & $5(13.5)$ & $1(16.7)$ & \\
\hline No abuse & $73(80.2)$ & $53(88.3)$ & $32(86.5)$ & $5(83.3)$ & \\
\hline \multicolumn{6}{|l|}{ Physical abuse (n [\%]) } \\
\hline Before adolescence & & & & & $1.1^{\mathrm{a}}$ \\
\hline Abuse & $22(24.2)$ & $14(23.3)$ & $6(16.2)$ & $1(16.7)$ & \\
\hline No abuse & $69(75.8)$ & $46(76.7)$ & $31(83.8)$ & $5(83.3)$ & \\
\hline After adolescence & & & & & $3.1^{\mathrm{a}}$ \\
\hline Abuse & $12(13.2)$ & $3(5.0)$ & $5(13.5)$ & $1(16.7)$ & \\
\hline No abuse & $79(86.8)$ & $57(95.0)$ & $32(86.5)$ & $5(83.3)$ & \\
\hline
\end{tabular}

${ }^{a}$ Not significant.

IBS, irritable bowel syndrome; IBS-D, diarrhea-predominant IBS; IBS-C, constipation-predominant IBS, IBS-M, mixed IBS; IBS-U, unsubtyped IBS; $\chi^{2}$, Pearson's chi-square test.

\section{Hospital Anxiety and Depression Scale, Sleep Difficulty, and Abuse History}

IBS patients with a history of sexual abuse, either before or after adolescence, had higher HADS (including both anxiety and depression subscales) scores (before adolescence: $23.3 \pm 5.2$ vs $12.8 \pm 5.8, P<0.001$; after adolescence: $22.0 \pm 6.2$ vs $13.1 \pm 6.1$, $P<0.001$ ), and higher frequencies of sleep difficulties than IBS patients without this history $(71.0 \%$ vs $39.9 \%, P<0.05)$. However, similar HADS scores and sleep quality were observed in IBS patients with and without a history of physical abuse (Table 4).

\section{Irritable Bowel Syndrome Subtype and Abuse History}

There were no significant differences between abuse prevalence (both sexual and physical) and IBS subtype (Table 5).

\section{Discussion}

In the current study, we first demonstrated that a higher rate of sexual abuse history can be identified in female IBS patients in Asia. We further indicated that IBS patients with a sexual abuse history in Taiwan had higher HADS scores and higher prevalence of sleep difficulty than patients without sexual abuse history. ${ }^{9,10}$ In Eastern societies, sexual abuse is often under-reported due to cultural attitudes regarding sexual restraint. ${ }^{22}$ Under-reporting of sexual abuse has even been reported in Asian populations emigrating overseas. ${ }^{23}$
Furthermore, not only are patients with a history of abuse reluctant to share this information with their family, but physicians in Eastern countries seldom or never have the chance to approach this issue due to very busy clinic schedules and insufficient knowledge about the relationship between sexual abuse and IBS symptoms. ${ }^{21}$ In the current study, we carefully obtained information on abuse history in a private condition in a setting free of interruptions. Though the possibility of under-reporting still exists, we nevertheless found that the prevalence of sexual abuse in IBS patients in Taiwan was approximately $16.0 \%$, which is comparable to those in Western countries. ${ }^{910,24,25}$ Most Western studies evaluate pre-adolescent sexual abuse history in IBS or other FGIDS, and the prevalence of sexual abuse has ranged between $11.0 \%$ and $57.0 \%$, depending on the methods of assessment and definitions of abuse used. ${ }^{9,10,24,25}$

We found that the prevalence of physical abuse was similar between IBS patients and controls. This rate of physical abuse was higher than that in Western societies (4.0\% in Drossman's study). Corporal punishment is commonly viewed by many Taiwanese parents as a legitimate and effective form of discipline. In a previous study from Taiwan, 22.2\% of adolescents living in rural Taiwan reported having experienced physical abuse. ${ }^{26}$ However, their definition of physical abuse was strict, including abrasions, bruises, or pain caused by physical injury that had to last to the second day. This strict definition might have led to an underestimation of the occurrence of physical abuse. Moreover, we have reported an approximately $22.0 \%$ prevalence of IBS diagnosed by Rome II criteria in healthy check-up examinations, which is one of the highest 
prevalences of IBS in Asian countries. ${ }^{17}$ Whether this high rate of history of physical abuse in Taiwan contributes to IBS symptoms warrants further investigation.

In Western courtiers, early life events, including abuse history, has been proven to relate with IBS symptoms. ${ }^{27}$ Similarly, abuse history during adulthood is also associated with IBS. ${ }^{9}$ Whether the abuse history before or after adolescence can contribute to IBS symptoms remains unknown in Asia. In this study, we also demonstrated that high prevalence of sexual abuse history, no matter before or after adolescence, commonly exists among IBS patients in Asia. Our results suggested that history of sexual abuse after adolescence can still be associated with IBS symptoms. We even identified that female patients having physical abuse after, but not before adolescence, is linked with IBS symptoms. Whether this shorter duration of the abuse history will have any impact on the abdominal symptoms and psychological profiles may need further evaluation.

IBS is usually female-predominant, although this trend seems to be non-significant in Asian countries. ${ }^{28}$ Nevertheless, in the current study, we found that female, but not male, IBS patients had a significantly higher prevalence of sexual abuse history both before and after adolescence, and of physical abuse history after adolescence than controls. In other words, female gender contributed to the group differences regarding the increased history of abuse in IBS patients. This finding was consistent with those from Western settings. ${ }^{9,10,27}$ However, this lack of difference in males may be caused by the relatively smaller sample size of male IBS patients compared with that of their female counterparts. Future larger studies enrolling more men are needed to clarify this issue.

In this study, a high HADS score and a high prevalence of sleep difficulties were identified among female IBS patients with a sexual abuse history in Taiwan. Sexual abuse can lead to a high anxiety status and sleep disorders, as has been widely documented. ${ }^{29-36}$ In Taiwan, we have also previously demonstrated a higher prevalence of sleep difficulty in IBS patients than in controls. ${ }^{17}$ The above findings suggest that sexual abuse may lead to stress and subsequent peripheral sensitization and abnormal pain processing in the brain, which may contribute to the development of IBS symptoms as well as to its associated psychological and sleep difficulty. Neurobiological mechanisms underlying the association between abuserelated stress and IBS have been identified both in animal models and in human beings. In animal studies, stress before adolescence would result in alterations in the hypothalamic-pituitary-adrenal axis regulation, enhanced visceral hypersensitivity and increased defecation in adult rats. ${ }^{37,38}$ In adult subjects or IBS patients, acute stress would also increase small intestinal permeability and altered central processing of visceral stimuli. ${ }^{39,40}$ For this group of IBS patients, treatment directed towards psychiatric conditions is essential to contribute to a reduction in symptom severity. ${ }^{41}$

To the best of our knowledge, no sexual abuse data in association with IBS are available in Asia. Our current data suggest that inquiring about abuse history is important in managing IBS patients, especially in the era of Rome IV. A Multidimensional Clinical Profile (MDCP) is suggested by the Rome IV committee as the standard approach in FGID (including IBS) patients. ${ }^{42}$ MDCPs aim to assess the individual aspects of a given patient's physiological, psychological or social situation or history that could affect IBS symptoms. A recent systematic review and meta-analysis also suggested combining bowel symptoms with biomarkers and/or markers of psychological affect to obtain a more accurate diagnosis of IBS. ${ }^{43}$ This approach may be more intuitive than using symptom-based criteria alone, as it takes into account the likely composite nature of IBS.

This study is subject to limitations due to its cross-sectional design. Therefore, the causal relationships between abuse history and IBS symptom, sleep difficulty, and psychological profiles are still uncertain. Furthermore, the reported abuse history that happened decades ago will be accompanied by concerns about the recall or self-report biases. In addition, this study was conducted in a tertiary medical center in Taiwan and it is unknown whether our findings can be extended to the general population.

In conclusion, a high prevalence of sexual abuse history with higher HADS scores and sleep difficulty were common in female IBS patients in Taiwan. We strongly suggest obtaining abuse history when using the MDCP approach for IBS patients in Asia, as this measurement will help improve strategies to manage this patient population.

Financial support: This study was supported by grants from the Taipei Veterans General Hospital (V102B-019 and V103B-034).

\section{Conflicts of interest: None.}

Author contributions: Study concept and design: Hsing-Feng Lee and Ching-Liang Lu; acquisition of data: Hsing-Feng Lee, Pei-Yi Liu, and Ching-Liang Lu; statistical analysis: Hsing-Feng Lee; technical support: Chia-Fen Tsai, Yen-Po Wang, and Pei-Yi Liu; wrote the manuscript: Hsing-Feng Lee and Ching-Liang $\mathrm{Lu}$; study supervision: Yen-Po Wang, Chia-Fen Tsai, Full-Young Chang, and Ching-Liang Lu; and guarantor of the article: ChingLiang Lu. 


\section{References}

1. Agrawal A, Whorwell PJ. Irritable bowel syndrome: diagnosis and management. BMJ 2006;332:280-283.

2. Drossman DA, Camilleri M, Mayer EA, Whitehead WE. AGA technical review on irritable bowel syndrome. Gastroenterology 2002;123:21082131.

3. Talley NJ, Spiller R. Irritable bowel syndrome: a little understood organic bowel disease? Lancet 2002;360:555-564.

4. Chey WY, Jin HO, Lee MH, Sun SW, Lee KY. Colonic motility abnormality in patients with irritable bowel syndrome exhibiting abdominal pain and diarrhea. Am J Gastroenterol 2001;96:1499-1506.

5. Chadwick VS, Chen W, Shu D, et al. Activation of the mucosal immune system in irritable bowel syndrome. Gastroenterology 2002;122:17781783.

6. Talley NJ, Gabriel SE, Harmsen WS, Zinsmeister AR, Evans RW. Medical costs in community subjects with irritable bowel syndrome. Gastroenterology 1995;109:1736-1741.

7. Levy RL, Von Korff M, Whitehead WE, et al. Costs of care for irritable bowel syndrome patients in a health maintenance organization. Am J Gastroenterol 2001;96:3122-3129.

8. Chitkara DK, van Tilburg MA, Blois-Martin N, Whitehead WE. Early life risk factors that contribute to irritable bowel syndrome in adults: a systematic review. Am J Gastroenterol 2008;103:765-774.

9. Drossman DA, Leserman J, Nachman G, et al. Sexual and physical abuse in women with functional or organic gastrointestinal disorders. Ann Intern Med 1990;113:828-833.

10. Talley NJ, Fett SL, Zinsmeister AR, Melton LJ 3rd. Gastrointestinal tract symptoms and self-reported abuse: a population-based study. Gastroenterology 1994;107:1040-1049.

11. Leserman J, Li Z, Drossman DA, Hu YJ. Selected symptoms associated with sexual and physical abuse history among female patients with gastrointestinal disorders: the impact on subsequent health care visits. Psychol Med 1998;28:417-425.

12. Drossman DA, Li Z, Leserman J, Toomey TC, Hu YJ. Health status by gastrointestinal diagnosis and abuse history. Gastroenterology 1996;110:999-1007.

13. Hobbis IC, Turpin G, Read NW. A re-examination of the relationship between abuse experience and functional bowel disorders. Scand J Gastroenterol 2002;37:423-430.

14. Fond G, Loundou A, Hamdani N, et al. Anxiety and depression comorbidities in irritable bowel syndrome (IBS): a systematic review and metaanalysis. Eur Arch Psychiatry Clin Neurosci 2014;264:651-660.

15. Alander T, Heimer G, Svärdsudd K, Agreus L. Abuse in women and men with and without functional gastrointestinal disorders. Dig Dis Sci 2008;53:1856-1864.

16. Lee YY, Waid A, Tan HJ, Chua SB, Whitehead WE. Validity and reliability of the Malay-language translation of the Rome III Diagnostic Questionnaire for irritable bowel syndrome. J Gastroenterol Hepatol 2011;27:746-750.

17. Lu CL, Chen CY, Lang HC, et al. Current patterns of irritable bowel syndrome in Taiwan: the Rome II questionnaire on a Chinese population. Aliment Pharmacol Ther 2003;18:1159-1169.

18. Drossman DA, Hasler WL. Rome IV-functional GI disorders: disorders of gut-braininteraction. Gastroenterology 2016;150:1257-1261.

19. Briere JN, Elliott DM. Immediate and long-term impacts of child sexual abuse. Future Child 1994;4:54-69.

20. Lee HF, Hsieh JC, Lu CL, et al. Enhanced affect/cognition-related brain responses during visceral placebo analgesia in irritable bowel syndrome patients. Pain 2012;153:1301-1310.

21. Drossman DA, Talley NJ, Leserman J, Olden KW, Barreiro MA. Sexual and physical abuse and gastrointestinal illness. Review and recommendations. Ann Intern Med 1995;123:782-794.

22. Ho TP, Kwok WM. Child sexual abuse in Hong Kong. Child Abuse Negl 1991;15:597-600.

23. Meston CM, Heiman JR, Trapnell PD, Carlin AS. Ethnicity, desirable responding, and self-reports of abuse: a comparison of European- and Asian-ancestry undergraduates. J Consult Clin Psychol 1999;67:139144.

24. Senn TE, Carey MP, Vanable PA. Childhood and adolescent sexual abuse and subsequent sexual risk behavior: evidence from controlled studies, methodological critique, and suggestions for research. Clin Psychol Rev 2008;28:711-735.

25. Han C, Masand PS, Krulewicz S, et al. Childhood abuse and treatment response in patients with irritable bowel syndrome: a post-hoc analysis of a 12-week, randomized, double-blind, placebo-controlled trial of paroxetine controlled release. J Clin Pharm Ther 2009;34:79-88.

26. Yen CF, Yang MS, Yang MJ, Su YC, Wang MH, Lan CM. Childhood physical and sexual abuse: prevalence and correlates among adolescents living in rural Taiwan. Child Abuse Negl 2008;32:429-438.

27. Bradford K, Shih W, Videlock EJ, et al. Association between early adverse life events and irritable bowel syndrome. Clin Gastroenterol Hepatol 2012;10:385-390, e1-e3.

28. Lovell RM, Ford AC. Effect of gender on prevalence of irritable bowel syndrome in the community: systematic review and meta-analysis. Am J Gastroenterol 2012;107:991-1000.

29. Noll JG, Trickett PK, Susman EJ, Putnam FW. Sleep disturbances and childhood sexual abuse. J Pediatr Psychol 2006;31:469-480.

30. Collado-Corona MA, Loredo-Abdalá A, Serrano-Morales JL, Shkurovich-Bialik P, Shkurovich-Zaslavsky M, Arch-Tirado E. [Sleep alterations in childhood victims of sexual and physical abuse]. Cir Cir 2005;73:297301. [Spanish]

31. Lind MJ, Aggen SH, Kendler KS, York TP, Amstadter AB. An epidemiologic study of childhood sexual abuse and adult sleep disturbances. Psychol Trauma 2016;8:198-205.

32. Steine IM, Harvey AG, Krystal JH, et al. Sleep disturbances in sexual abuse victims: a systematic review. Sleep Med Rev 2012;16:15-25.

33. Kajeepeta S, Gelaye B, Jackson CL, Williams MA. Adverse childhood experiences are associated with adult sleep disorders: a systematic review. Sleep Med 2015;16:320-330.

34. Kamiya Y, Timonen V, Kenny RA. The impact of childhood sexual abuse on the mental and physical health, and healthcare utilization of older adults. Int Psychogeriatr 2016;28:415-422. 
35. Chen LP, Murad MH, Paras ML, et al. Sexual abuse and lifetime diagnosis of psychiatric disorders: systematic review and meta-analysis. Mayo Clin Proc 2010;85:618-629.

36. Paolucci EO, Genuis ML, Violato C. A meta-analysis of the published research on the effects of child sexual abuse. J Psychol 2001;135:17-36.

37. Coutinho SV, Plotsky PM, Sablad M, et al. Neonatal maternal separation alters stress-induced responses to viscerosomatic nociceptive stimuli in rat. Am J Physiol Gastrointest Liver Physiol 2002;282:G307-G316.

38. Gareau MG, Jury J, Perdue MH. Neonatal maternal separation of rat pups results in abnormal cholinergic regulation of epithelial permeability. Am J Physiol Gastrointest Liver Physiol 2007;293:G198-G203.

39. Vanuytsel T, van Wanrooy S, Vanheel H, et al. Psychological stress and corticotropin-releasing hormone increase intestinal permeability in humans by a mast cell-dependent mechanism. Gut 2014;63:1293-1299.
40. Elsenbruch S, Rosenberger C, Enck P, Forsting M, Schedlowski M, Gizewski ER. Affective disturbances modulate the neural processing of visceral pain stimuli in irritable bowel syndrome: an fMRI study. Gut 2010;59:489-495.

41. Bennett EJ, Tennant CC, Piesse C, Badcock CA, Kellow JE. Level of chronic life stress predicts clinical outcome in irritable bowel syndrome. Gut 1998;43:256-261.

42. Drossman DA. Functional gastrointestinal disorders: history, pathophysiology, clinical features and Rome IV. Gastroenterology 2016;150:12621279, e2.

43. Sood R, Gracie DJ, Law GR, Ford AC. Systematic review with metaanalysis: the accuracy of diagnosing irritable bowel syndrome with symptoms, biomarkers and/or psychological markers. Aliment Pharmacol Ther 2015;42:491-503. 